\title{
THE GASTRIC SECRETION IN CHRONIC ALCOHOLIC ADDICTION
}

\author{
By W. B. SEYMOUR, TOM DOUGLAS SPIES, AND WARREN PAYNE \\ (From the Department of Medicine, Western Reserve University, School of Medicine, and the \\ Lakeside Hospital, Cleveland)
}

(Received for publication August 2, 1938)

The present study is concerned with the status of gastric secretion in individuals chronically addicted to the use of large quantities of ethyl alcohol. Prolonged overindulgence in spiritous liquors has long been cited as one of the foremost causes of chronic gastritis and deficient gastric secretion. Hirsch (1) studied histologically the stomachs of 22 individuals dying from delirium tremens, and although 3 showed mucoid degeneration, none showed any active inflammatory process. Thomsen (2) administered large quantities of alcohol to one dog by means of a Pavlov pouch, over a 2-year period. A gradual change from acute to chronic inflammation was observed histologically; there was a decrease in the volume of juice secreted, but no change in the acidity or peptic activity.

Seidelin (3) conducted a clinical study of gastric secretion on elderly individuals with various diseases, using the Ewald test meal. Among 14 cases of chronic alcoholism, 7 showed anacidity, 1 hypoacidity, and 6 normal acidity. Peptic digestion was only slightly, if at all, impaired. Vogelius (4) studied 83 cases of chronic uncomplicated alcoholism, using the Ewald meal, and found 41 with achlorhydria, 13 with hypochlorhydria, and 29 with normal acidity. Merritt and Moore (5) observed 8 alcoholics with associated neuritis resulting from ingestion of impure Jamaica ginger (containing tri-orthocresyl phosphate). Seven of the 8 showed normal gastric acidity. Minot, Strauss, and Cobb (6) studied the gastric acidity of 43 patients with "alcoholic" neuritis, using the alcohol test meal. Of these 15 had hypoacidity and 21 anacidity. Ten of the latter showed no free acid in the gastric juice even after the subcutaneous administration of histamine. These investigators suggested that the incidence of hypoand anacidity was greater in "alcoholic" polyneuritis than in simple chronic alcoholism, ascribing the difference to a deficiency factor. Villaret et al. (7) reported 50 cases of "alcoholic" polyneuritis, using $1 \mathrm{mgm}$. of histamine subcutaneously on each subject. Of these, 33 had achlorhydria, 12 hypochlorhydria, and 5 normal acidity. Joffe and Jolliffe (8) observed 105 chronic alcoholics, using the alcohol test meal; histamine was given only when no acid was obtained after alcohol. Twenty-seven of their patients had pellagra, 74 had polyneuritis, and 26 were uncomplicated. They indicated that the greater incidence of achlorhydria in their polyneuritic group could be ascribed to a deficiency of the vitamin $B$ complex.

The results of the above investigators, together with those of the present investigation, are presented in Tables I and II.

TABLE I

Gastric juice in uncomplicated chronic alcoholism (Results of various investigators)

\begin{tabular}{c|c|c|c|c|c}
\hline \hline & $\begin{array}{c}\text { Num- } \\
\text { ber } \\
\text { of } \\
\text { pa- } \\
\text { tients }\end{array}$ & Secretory stimulus & $\begin{array}{c}\text { Nor- } \\
\text { mal } \\
\text { acid }\end{array}$ & $\begin{array}{c}\text { Hypo- } \\
\text { chlor- } \\
\text { hydria }\end{array}$ & $\begin{array}{c}\text { Achlor- } \\
\text { hydria }\end{array}$ \\
\hline & 14 & $\begin{array}{c}\text { Ewald } \\
\text { Seidelin (3).. }\end{array}$ & $\begin{array}{c}\text { per cent } \\
43\end{array}$ & $\begin{array}{c}\text { per cent } \\
7\end{array}$ & $\begin{array}{c}\text { per cent } \\
50 \\
\text { Vogelius (4).. }\end{array}$ \\
$\begin{array}{c}\text { Joffe and (8) } \\
\text { Jolliffe (8). }\end{array}$ & 26 & $\begin{array}{l}\text { Alcohol; histamine } \\
\text { on 1 patient }\end{array}$ & 58 & 16 & 49 \\
$\begin{array}{c}\text { Present in- } \\
\text { vestigators }\end{array}$ & 40 & Histamine 0.5 gram & 5 & 57.5 & 37.5 \\
\hline
\end{tabular}

TABLE II

Gastric juice in chronic alcoholism with polyneuritis (Results of various investigators)

\begin{tabular}{|c|c|c|c|c|c|}
\hline Investigator & $\begin{array}{c}\text { Num- } \\
\text { ber } \\
\text { of } \\
\text { pa- } \\
\text { tients }\end{array}$ & Secretory stimulus & $\begin{array}{l}\text { Nor- } \\
\text { mal } \\
\text { acid }\end{array}$ & $\begin{array}{l}\text { Hypo- } \\
\text { chlor- } \\
\text { hydria }\end{array}$ & $\begin{array}{l}\text { Achlor- } \\
\text { hydria }\end{array}$ \\
\hline $\begin{array}{l}\text { Minot, Strauss, } \\
\text { and Cobb (6). } \\
\text { Villaret et al. (7)... } \\
\text { Joffe and Jolliffe } \\
\text { (8) ........... }\end{array}$ & $\begin{array}{l}50 \\
74\end{array}$ & $\begin{array}{l}\text { Alcohol; histamine } \\
\text { on } 10 \text { patients } \\
\text { Histamine } 1.0 \text { mgm. } \\
\text { Alcohol; histamine } \\
\text { on patients with } \\
\text { achlorhydria after } \\
\text { alcohol }\end{array}$ & $\begin{array}{l}\text { per } \\
\text { cent } \\
16 \\
10\end{array}$ & $\begin{array}{l}\text { per } \\
\text { cent } \\
\\
35 \\
24\end{array}$ & $\begin{array}{l}\text { per } \\
\text { cent } \\
49 \\
66\end{array}$ \\
\hline
\end{tabular}

The pellagrins of Joffe and Jolliffe's series are omitted from the above, as well as Merritt and Moore's patients with specific neuritis.

Our study was carried out on 40 men, all heavy drinkers, the period of consumption of liquor varying from 7 to 40 years, the daily amount consumed varying from one to three pints of liquor. 
They had all been committed to jail for repeated drunkenness. On the morning following their committment a gastric tube was passed, the entire fasting content of the stomach was withdrawn, and $0.5 \mathrm{mgm}$. of histamine $(1.5 \mathrm{mgm}$. ergamine acid phosphate of Burroughs-Wellcome) was given subcutaneously. After a lapse of $20 \mathrm{~min}$ utes, the entire gastric content was again withdrawn. A red blood count and a hemoglobin determination were done on each subject; no smears were examined. If achlorhydria was found after histamine had been given, a gastric tube was again passed after a lapse of 1 to 3 weeks, histamine was again given, and the gastric content was withdrawn 20 minutes later.

The volume of each complete specimen was recorded. Free hydrochloric acid was determined by titration with $0.1 \mathrm{~N}$ sodium hydroxide, using Töpfer's reagent as an indicator. Peptic power was estimated by the Mett tube method, the number of millimeters of albumin digested being an index of activity. Rennin was determined by adding 5 drops of gastric juice to $10 \mathrm{cc}$. of milk, and incubating for 20 minutes. All determinations were made with filtered gastric juice.

In comparing our results with the normal, we have used as standards the values tabulated by Bloomfield and Polland (9).

\section{RESULTS AND COMMENT}

The fasting volume upon repeated intubation was scanty, and in the majority of cases was rather thick and ropy. Seventy-one per cent of the cases had a volume of 20 cc. or less. After histamine injection the gastric juice was considerably more limpid, and had increased in volume, 50 per cent of the cases showing $20 \mathrm{cc}$. or more. However, in comparing these results with the normals of Bloomfield and Polland (Figure 1) it may be seen that our patients secreted a volume of juice definitely less than normal. Bloomfield and Polland's histogram represents volumes 10 minutes after histamine while ours is 20 minutes after histamine, so that in reality the volumes which we record are much lower than the normal than is apparent in the comparison of the two figures.

Only 2 of the 40 subjects had free acid in the fasting specimen. In the first analysis after histamine, 18 had free hydrochloric acid and 22 had

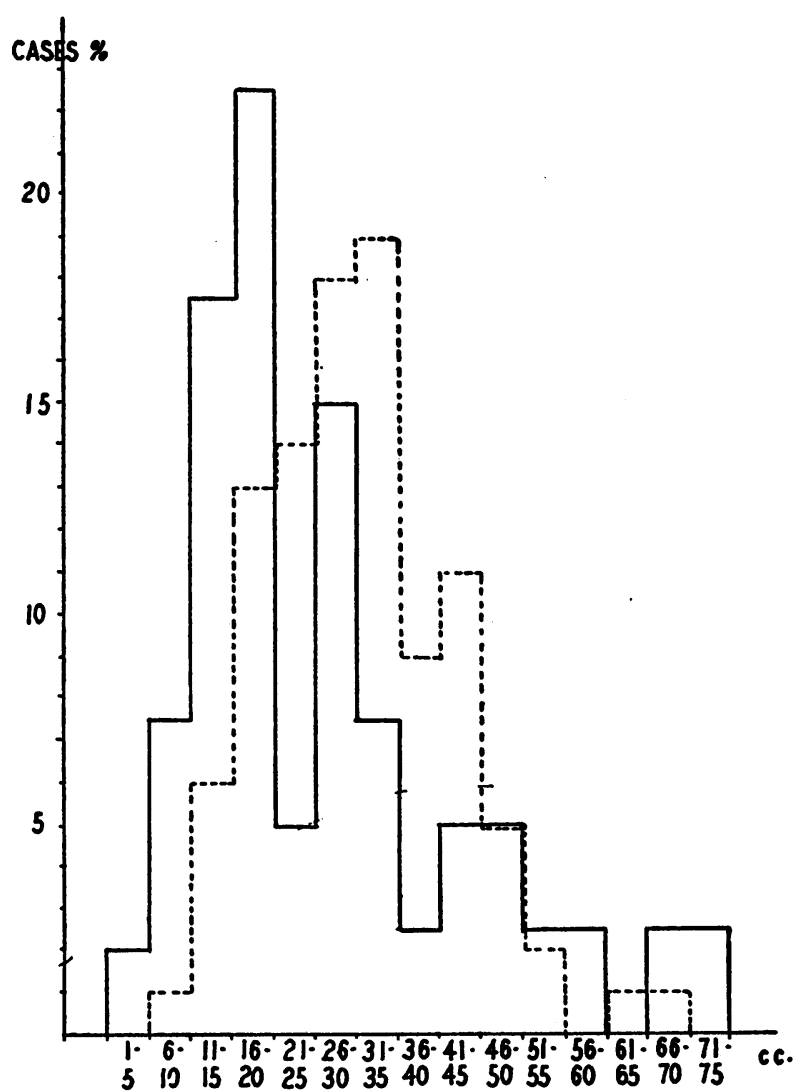

Fig. 1. Histogram Comparing the Fasting Secretory Volume after Histamine in Alcoholics aNd Normal Individuals

Solid lines: Present series of 40 alcoholics, volume secreted in 20 minutes. Interrupted lines: 100 normal people (after Bloomfield and Polland), volume secreted in 10 minutes.

none. The latter were all reintubated after 1 to 3 weeks had elapsed, and 7 of these showed free acid in the gastric juice after this period, the values obtained being $10,6,12,6,10,20$, and 32 . Thus the end result showed a total of 15 with achlorhydria and 25 with acid in the gastric juice, and 92 per cent of the latter had acid values of $50^{\circ}$ or less.

Comparison of the acid values obtained in our series upon repeat analyses with the normals of Bloomfield and Polland (Figure 2) shows a reduced secretion of acid in our series. These two figures are not strictly comparable, as our histogram represents the acidity 20 minutes after histamine while that of Bloomfield and Polland represents maximum acidity after histamine, the former being only about 83 per cent of the latter 


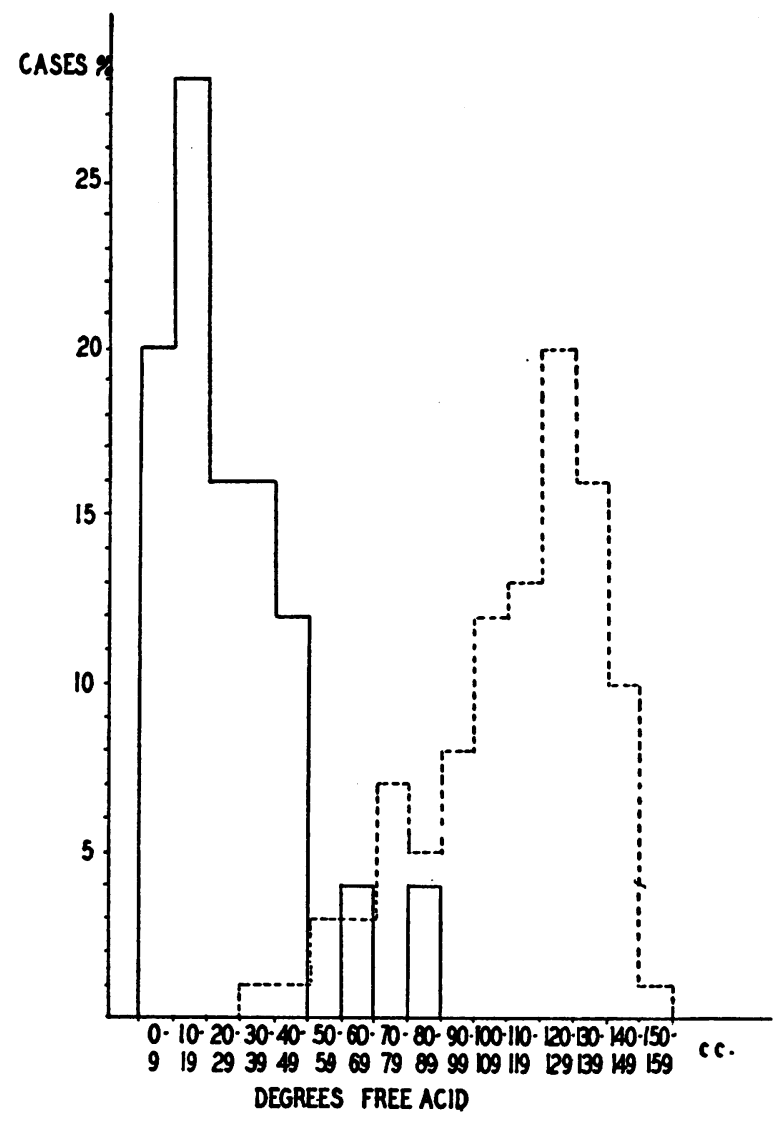

Fig. 2. Histogram Comparing the Secretion of Free Acid in Chronic Alcoholics and Normal INDIVIDUALS

Solid lines: Present series of 25 alcoholics, 20 minutes after histamine. Interrupted lines: Highest acidity after histamine in 100 normal individuals (after Bloomfield and Polland).

figure (9). Even with this correction, however, our figures still fall far short of normal.

Only 3 of our patients showed no evidence of pepsin in the gastric juice after repeated analyses, and 7 showed an absence of rennin. The mean digestion of albumin in our 37 cases was $3.5 \mathrm{~mm}$. The usual normal peptic power, measured in the Mett tube, is 2 to $4 \mathrm{~mm}$. of egg albumen. We attempt to draw no comparative conclusions from our findings, however, other than to state that Bloomfield and Polland consider peptic activity the most delicate index of gastric secretory function.

Our patients were singularly free from gastrointestinal complaints. Thirty-two claimed to have good appetites; 12 complained of gas; and 8 com- plained of sour eructations. Intermittent nausea and vomiting were experienced by 6 . In none was there any history of sore tongue, skin lesions, or diarrhea, nor was there any objective evidence of glossitis.

Six patients complained of only occasional numbness and burning sensations of the extremities, and none had any objective evidence of involvement of the peripheral nerves. In all subjects the red blood counts and hemoglobin determinations were normal.

The age incidence of our group with achlorhydria is shown in Figure 3, and shows an increased incidence over the normal.

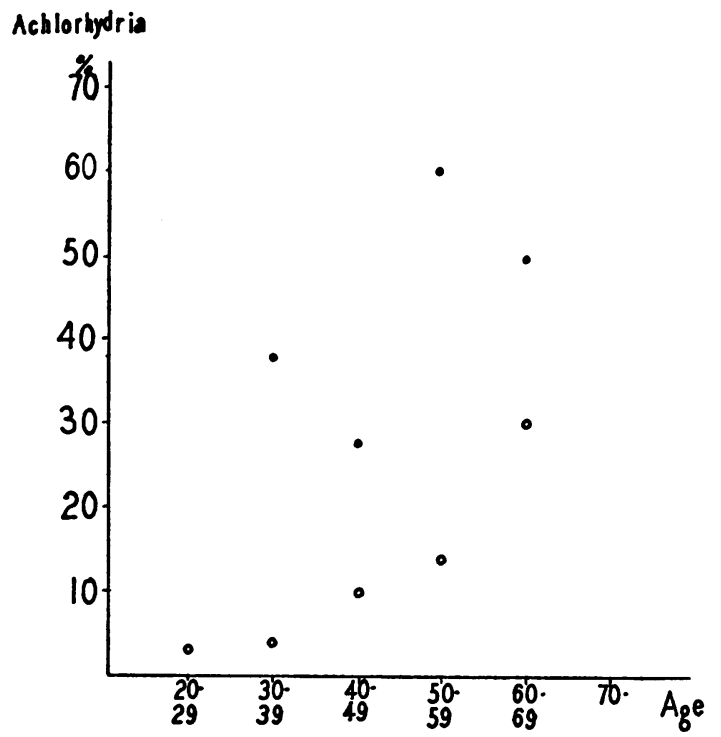

Fig. 3. Decade Inctdence of AchlorhydrIa after Histamine

Dots : Incidence in present series of alcoholics. Circles : Incidence in 644 normal individuals (after Polland).

It is to be emphasized that we did repeated analyses on all subjects with achlorhydria after histamine in the initial analysis, and that 7 yielded free hydrochloric acid after histamine following enforced abstinence from alcohol. This point is significant not only in its application to the interpretation of the results obtained by ourselves and others, but also in its suggestion of the relationship of the ingestion of large quantities of alcohol to the secretion of acid in the gastric juice.

We do not consider our results strictly comparable to those of other investigators except to those of Villaret et al., who also used histamine 
as a stimulus to secretion throughout (7). Villaret's cases all had polyneuritis complicating chronic alcoholism, whereas ours had no polyneuritis. It is apparent that the incidence of achlorhydria is far higher in alcoholics with polyneuritis than in those with uncomplicated alcoholism (Tables I and II), a suggestion first made by Minot, Strauss, and Cobb (6).

\section{SUMMARY}

The gastric secretion in 40 chronic alcoholic addicts was studied, histamine being used as a secretory stimulant. There was no clinical evidence of vitamin deficiency, and no laboratory evidence of anemia. The results show an average diminished secretory volume and an average diminished acidity, but the peptic activity of the gastric juice was apparently unimpaired. Comparison of the incidence of the achlorhydria which we found with the expected normal incidence for the various age groups shows a conisiderable increase of achlorhydria over normal. Comparison of the incidence of achlorhydria in our series with a series of alcoholics with polyneuritis in which histamine was used as a secretory stimulant shows that the percentage with achlorhydria was much higher in the latter group.

\section{CONCLUSIONS}

1. The present study shows that the ingestion of large quantities of alcoholic liquors by human beings over a number of years causes a diminution in the volume of gastric juice secreted, a diminution in the acidity of gastric juice, an increased incidence of achlorhydria, and little or no change in the peptic activity of the gastric juice.

2. A single gastric analysis following histamine is not sufficient to determine true achlorhydria, as a repeat analysis following histamine may demonstrate free acid where none was previously found.

3. Interpretation of these findings in the light of other investigations suggests that the incidence of achlorhydria is higher in persons with alcoholic addiction and polyneuritis than in uncomplicated chronic alcoholics.

\section{BIBLIOGRAPHY}

1. Hirsch, E. F., The gastric mucosa in delirium tremens. Arch. Int. Med., 1916, 17, 354.

2. Thomsen, E., Etudes sur L'Achylie Neurogene et Cellulaire. Acta med. Scandinav., 1925, 61, 377, 522.

3. Seidelin, $H$., Untersuchungen des Mageninhaltes bei Älteren Individuen. Berl. Klin. Wchnschr., 1904, 41, 945.

4. Vogelius, F., Dyspepsie beim chronischen Alkoholismus. Arch. f. Verdauungskr., 1918, 24, 278.

5. Merritt, H. H., and Moore, M., Peripheral neuritis associated with ginger extract ingestion. New England J. Med., 1930, 4, 203.

6. Minot, G. R., Strauss, M. B., and Cobb, S., "Alcoholic" polyneuritis; dietary deficiency as a factor in its production. New England J. Med., 1933, 208, 1244.

7. Villaret, M., Montier, F., Justin-Besançon, L., and Klotz, H., Caractère Spécial des Troubles Gastriques au cours de la Polynevrite Alcoölique. Bull. et mem. Soc. med. d. hôp. de Paris, 1936, 52 (pt. 2), 1155.

8. Joffe, P., and Jolliffe, N., The gastric acidity in alcoholic addicts. Am. J. M. Sc., 1937, 193, 501.

9. Bloomfield, A., and Polland, W., Gastric Anacidity, The Macmillan Co., New York, 1933. 